\title{
Dermal Cylindroma Is a Histological Surprise:A Case Report
}

\author{
Chaitanya Kumar Reddy $\mathrm{P}^{1}$, Harris Mohammed $\mathrm{P}^{1}$, Prashanth $\mathrm{K}^{1}$, Shekar Y \\ Tati $^{1}$, Gopinath Pai ${ }^{1}$, Chidananda K V ${ }^{1}$, Ganapathi Puranik ${ }^{1}$, Karumbaiah K P ${ }^{2}$. \\ ${ }^{I}$ Department of General Surgery, KVG Medical College and Hospital, Sullia, DK, Karnataka, India. \\ ${ }^{2}$ Department of Pathology, KVG Medical College and Hospital, Sullia, DK, Karnataka, India.
}

\begin{abstract}
Dermal cylindromas are benign neoplasms arising from the eccrine sweat glands. Head and neck area is the most common site and scalp is extensively involved. The tumour can occasionally arise from the trunk and extremeties.Thetumour can present as a solitary or multiple tumors. Multiple tumours are more common in the scalp and are inherited by an autosomal dominant gene. Solitary cylindromas occur sporadically, not inherited and commonly located in the neck, trunk and extremities. We have come across a case of dermal cylindroma in 55 years old man. The tumor was arising from trunk; just below the right clavicle. It is a very rare tumor and further rare in the trunk. Clinically it is difficult to differentiate from sebaceous cyst. In our case also we diagnosed as sebaceous cyst. We are presenting this because it is a rare entity that too it is further rare on the trunk. Clinically it is impossible to diagnose and the diagnosis of cylindroma is a histological surprise.
\end{abstract}

Keywords: Dermal cylindroma, Germline mutations, Multiple cylindromas, Multiple familial trichoepitheliomas.

\section{Introduction}

Cylindromas are skin appendage tumours usually arising from straight part of the eccrine sweat gland. They may occur as solitary or multiple lesions. Multiple lesions are more common in the scalp. In the scalp they present as numerous small papules and/or large dome-shaped nodules like a turban; hence the name turban tumour was ascertained. Occasionally multiple nodules can also present on the face and rarely on the extremities [1]. Multiple cylindromas may also associate with other cutaneous and extracutaneous tumors [2]. Multiple tumours commonly occur in young individuals with inactivating mutation of tumour suppressor gene CYLD.

Germline mutations in this gene are associated with several related genetic syndromes including familial cylindromatosis, multiple familial trichoepitheliomas or both above mentioned varieties can occur as Brooke-Spiegler syndrome[3]. Solitary cylindromas occur sporadically, inherited tumours are commonly located in the neck, trunk and extremities.

Clinically most of the skin appendage tumours mimic like sebaceous cyst and provisional diagnosis can be sebaceous cyst or infected sebaceous cyst. Cylindroma or trichilemmoma is a surprise histological diagnosis. In our case also we diagnosed as sebaceous cyst and later cylindroma was a histological surprise.

\section{Case Report}

A 55year old male presented with a swelling over the right medial infra clavicular region since 30years which gradually progressed to a size of $6 \times 5 \mathrm{~cm}$. On examination the swelling was horizontally oval in shape, soft, cystic and fluctuant with mild tenderness. It was reddish pink in color. The surface of the swelling was smooth but lobulated (fig, 1). It was diagnosed as a dermal lesion since skin was not pinchable and helplessly it was diagnosed as infected sebaceous cyst since we were not able to consider any other specific diagnosis.

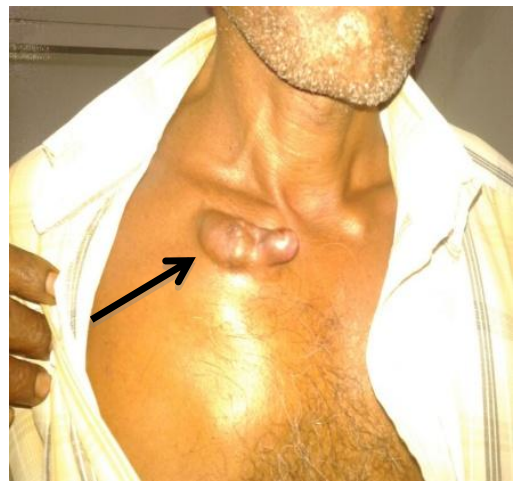

Figure 1 -Lobulated mass below the right clavicle. 
After routine investigations, the mass was excised under local anesthesia. Excised mass was reddish brown in color, firm and nodular. Cysticspace was found inside the nodule (fig.2). Specimen was sent for histological examination.

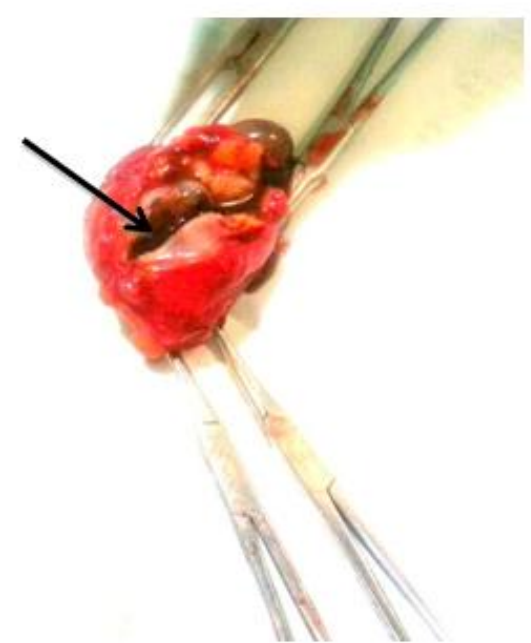

Figure 2 -Specimen with firm nodular mass showing cavity.
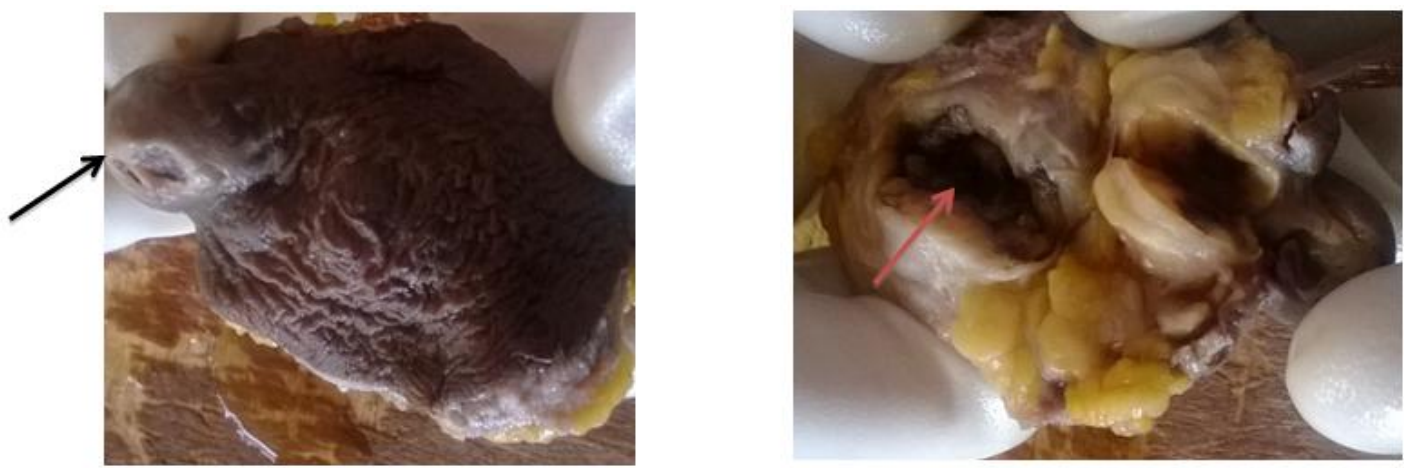

Figure 3A- Gross specimen.Figure 3B- Cut section showing cavity

Gross specimen was gray brown tissue measuring $5 \mathrm{X} 4 \mathrm{X} 1 \mathrm{~cm}$ in size with skin intact (Fig 3A). Small oval growth was seen over the outer aspect of tissue measuring $2 \mathrm{X} 1.5 \mathrm{X} 0.5 \mathrm{~cm}$. Cut section was showing two small grayish brown nodules below the skin surface (Fig 3B).

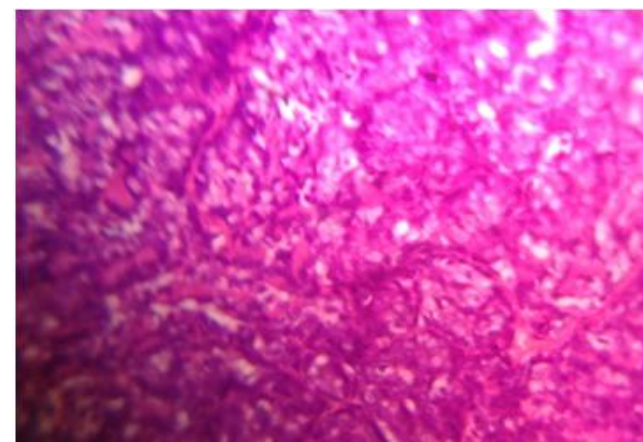

Figure 4 -Microscopic picture showing sheets and nests of epithelial cells (Hematoxylin and Eosin stain, 40X).

Microscopic picture was showing skin with nodular lesion. The nodule was located in the dermis composed of sheets and nests of epithelial cells. The tumor nest cells are deeply stained with pale nuclei and peripheral palisading. Cell nests are surrounded by eosinophilic hyaline sheath. Focal areas show proliferating ducts containing secretions in the lumen. Hyaline droplet material is also seen in the tumor cell nests. Impression was cylindorma (Fig.4). 


\section{Discussion}

Cylindromas are skin appendage tumours usually arising from straight part of the eccrine sweat gland but was previously thought to be of apocrine in origin.Recent immunohistological and cytomorphological studies have shown that the tumor exhibits apocrine, eccrine, secretory, and ductal features. Therefore, the cellular origin of cylindromas remains unknown. Cylindromas are most likely a very primitive sweat gland tumor differentiating towards either the eccrine or apocrine line.

Dermal cylindromas are benign neoplasms arising from head and neck area followed by trunk and extremities. Cylindromas can occur as solitary or multiple lesions. Solitary tumours are more common in the trunk where as multiple tumours are common on the scalp. Sometimes crop like tumors arise from the scalp looking like a turban called as turban tumours. Occasionally multiple tumors can arise from the face but rarely over the neck [1]. Multiple cylindromas may also occur in the trunk and extracutaneous sites [2]. Less than 10\% cylindromas are situated on the trunk and limbs [3].

Multiple tumours commonly occur in young individual with inactivating mutation of tumour suppressor gene CYLD. Germline mutation in this gene is associated with several genetic related syndromes including familial cylindromatosis, multiple familial trichoepitheliomas or both above mentioned varieties can occur as Brooke-Spiegler syndrome $(3,4,5, \& 6)$. The Brooke-Spiegler syndrome sometimes associates with unilateral hearing loss (7). The cause of sporadic, solitary cylindromas is largely unknown; however, genetic studies of sporadic cylindromas show loss of heterozygosity at and around the CYLD locus in a substantial number of cases, suggesting that this gene also plays a role in the development of sporadic tumors.

The tumor is usually oval in shape, soft, cystic and fluctuant. The surface of the tumor is smooth and even but sometimes the surface may be uneven with one or two lobulations, as seen in our case. Clinically most of the skin appendage tumours mimic like sebaceous cyst and provisional diagnosis is invariably sebaceous cyst since it is the most common appendecialtumour. Cylindroma or trichilemmoma is a surprise histological diagnosis since clinically both are rare and there are no specific clinical features of their own. In our case also we diagnosed as sebaceous cyst and cylindroma was a histological surprise.

Histopathologicallycylindroma is a dermal tumor arising from ductal element. The lesion is composed of numerous oval and polygonal nests of cells. Masses of epithelial cells are surrounded by a hyaline sheath closely resembling a basement membrane[8]. A lack of lymphoid tissueis a histological feature that differentiates cylindromas from spiradenomas. Cylindromas on the other hand, demonstrate a large number of prominent dendritic cells that most likely represent Langerhans cells that permeate the tumour[8].

Surgery is the treatment of choice. Tumour excision is sufficient. Other treatments include electrodessication/curettage.

\section{Conclusion}

Dermal cylindroma is a rare tumor in clinical practice. Cyindromas arise from the straight part of the duct of eccrine sweat gland but histochemical studies stress that tumor arises from primitive glandular elements of eccrine and apocrine glands. The cylindroma can present as solitary or multiple tumors. Solitary tumor is more common on the trunk where as multiple tumors are more common on the scalp. Both sporadic and multiple tumors are associated with genetic mutation. The tumor is commonly diagnosed as sebaceous cyst since sebaceous cyst is a common skin appendecial tumor. Surgical excision is the treatment of choice and cylindroma is a histological surprise.

\section{References}

[1]. Hashimoto K, Lever FW. "Tumours of the skin and appendages". In: Fitzpatrick TB, Arndt KA, Clark HW Jn, et al., editors. Dermatology in General Medicine. New York: McGraw Hill; 1971. p. 452.

[2]. Raman M, Singh N. "Familial multiple cylindromas". Indian J DermatolVenereolLeprol. 1991; 57:104-6.

[3]. Vinay kumar, Abul K. Abbas, Nelson Fausto, Jon C. Aster; Robbins and Cortan "Pathologic Basis of Diseases". Eighth edition, page. 1177.

[4]. Stegmeier F, Sowa ME, Nalepa G, Gygi SP, Harper JW, Elledge SJ. "The tumor suppressor CYLD regulates entry into mitosis". Proc NatlAcadSci U S A. 2007; 104:8869-74. [PMCID: PMC1867381] [PubMed: 17495026]

[5]. Massoumi R, Paus R. "Cylindromatosis and the CYLD gene: New lessons on the molecular principles of epithelial growth control". Bioessays. 2007; 29:1203-14. [PubMed: 18008375]

[6]. Fukuda M, Hiroi M, Suzuki S, Ohmori Y, Sakashita H."Loss of CYLD might be associated with development of salivary gland tumors". Oncol Rep. 2008;19:1421-7. [PubMed: 18497946]

[7]. $\quad$ Parren LJ, Bauer B, Hamm H, Frank J.” Brooke-Spiegler syndrome complicated by unilateral hearing loss”. Int J Dermatol. 2008; 47(Suppl 1):56-9. [PubMed: 18986490]

[8]. Carlson RM, Haddad L, Pui JC.” Brooke-Spiegler syndrome with associated pegged teeth”. Cutis. 2008; 82:345-9. [PubMed: 19090338] 